Die Schulen der Nation 
York-Gothart Mix

\section{Die Schulen der Nation}

Bildungskritik in der Literatur der Moderne

Verlag J.B. Metzler Stuttgart · Weimar 
Die Deutsche Bibliothek - CIP-Einheitsaufnahme

\section{Mix, York-Gothart:}

Die Schulen der Nation : Bildungskritik in der Literatur der Moderne / York-Gothart Mix.

- Stuttgart ; Weimar : Metzler, 1995

ISBN 978-3-476-01327-9

ISBN 978-3-476-01327-9

ISBN 978-3-476-05437-1 (eBook)

DOI 10.1007/978-3-476-05437-1

Dieses Werk einschließlich aller seiner Teile ist urheberrechtlich geschützt. Jede Verwertung außerhalb der engen Grenzen des Urheberrechtsgesetzes ist ohne Zustimmung des Verlages unzulässig und strafbar. Das gilt insbesondere für Vervielfältigungen, Ủbersetzungen, Mikroverfilmungen und die Einspeicherung und Verarbeitung in elektronischen Systemen.

(C) 1995 Springer-Verlag GmbH Deutschland

Ursprünglich erschienen bei J.B. Metzlersche Verlagsbuchhandlung und Carl Ernst Poeschel Verlag GmbH in Stuttgart 1995 
Ohne den Typus >less extroverted and more sensitive', ohne das -Ressentiment< der Schwäche, ohne ihre sittliche Intoleranz, ihren leidenden Kritizismus, dem die Wirklichkeit, wie sie ist, und wie sie den für sie Tüchtigen behagt, unerträglich ist - kurz, ohne den décadent, den kleinen Hanno, wären Menschheit und Gesellschaft seit diluvialen Zeiten um keinen Schritt vorwärtsgekommen.

Thomas Mann, Zu einem Kapitel aus 'Buddenbrooks`

Der Leser, von dem ich etwas erwarte, muß drei Eigenschaften haben. Er muß ruhig sein und ohne Hast lesen. Er muß nicht immer sich selbst und seine 'Bildung dazwischen bringen. Er darf endlich nicht, am Schlusse, etwa als Resultat, neue Tabellen erwarten. Tabellen und neue Stundenpläne für Gymnasien und andere Schulen verspreche ich nicht, bewundere vielmehr die überkräftige Natur jener, welche im Stande sind, den ganzen Weg, von der Tiefe der Empirie aus bis hinauf zur Höhe der eigentlichen Kulturprobleme und wieder von da hinab in die Niederungen der dürrsten Reglements und des zierlichsten Tabellenwerks, zu durchmessen; sondern zufrieden, wenn ich, unter Keuchen, einen ziemlichen Berg erklommen habe und mich oben des freieren Blicks erfreuen darf, werde ich eben in diesem Buche die Tabellenfreunde nie zufrieden stellen können.

Friedrich Nietzsche, Gedanken über die Zukunft unserer Bildungsanstalten 


\section{Inhaltsverzeichnis}

Vorbemerkung $\ldots \ldots \ldots \ldots \ldots \ldots \ldots \ldots \ldots \ldots \ldots \ldots \ldots \ldots \ldots \ldots \ldots \ldots \ldots$

Einleitung $\ldots \ldots \ldots \ldots \ldots \ldots \ldots \ldots \ldots \ldots \ldots \ldots \ldots$

I. Die Schulgeschichte als literarisches Genre . . . . . 13

I.1 Erziehung, Lehranstalt und Literatur. Thematische und motivische Traditionen der Schulgeschichte . . . . . . 16

I.2 Schulroman und Kadettengeschichte. Desillusionsromane anstelle von Bildungsromanen? . . . . . . . . 26

I.3 Handlungsmuster und Feindbilder. Schulische Sozialisation als literarisches Modethema $\ldots \ldots \ldots \ldots \quad 36$

II. Epik und Biographik zwischen introvertiertem Kritizismus und kritisch-denunziatorischer Wut . . 49

II.1 Introvertierter Kritizismus. R. M. Rilkes >Die Turn-

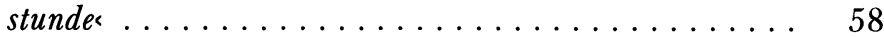

II.2 Ironie und Autoanalyse. Das Schlußkapitel in Th. Manns >Buddenbrooks‘ . . . . . . . . . . . . 73

II.3 Kritisch-denunziatorische Wut. H. Manns, Professor Unrat‘, A. Döblins , Gespenstersonate‘, L. Franks >Die Ursache und J. R. Bechers $>$ Abschied . ...............

III. Lehranstalt, Psychopathologie und Erzählliteratur . 97

III.1 Schulische Sozialisation als pathogenetischer Prozeß. G. Kellers > Der grüne Heinriche, H. Hesses >Unterm Rad und L. Franks >Die Ursache

III.2 Pubertäre Irritation und literarische Examination. F. Wedekind, R. Musil, E. Seyerlen, H. Fallada und die Selbstentfremdungserfahrung des Jugendlichen . . . . . . 130

II.3 Bürgerliche Pflichtethik und künstlerische Lebenskritik. H. Hesse, Th. Mann, A. Döblin, J. Roth und die

III.4 Pubertätsnarzißmus, Suizid und literarische Pathographie. H. Falladas $>$ Der junge Goedeschak, J. R. Bechers >Abschied` und H. Hesses >Unterm Rad 
IV. Bildungskritik, Reformpädagogik, Jugendbewegung und Schulgeschichte . . . . . . . . . . . . . 185

IV.1 Klassikerkult, Bildungsdünkel und die Not der Poesie an den Schulen. H. Hesse, H. Mann, Th. Mann und die Schulphilologie.

IV.2 Literarische Erziehungskritik und das Recht der Jugend. E. Strauß, H. Hesse, R. M. Rilke, W. Benjamin und die zeitgenössischen Reformbestrebungen . . . . . . 204

V. Die Schulgeschichte als Soziogramm des Obrigkeitsstaates .................... 217

V.1 Oberlehrer, Reserveoffizier, Schule und soldatischer Geist. G. Hauptmann, G. Heym, F. v. Unruh und der Obrigkeitsstaat .

V.2 Familie, Lehranstalt und Staat. Väter, Söhne und Generationskonflikte bei Th. Mann, E. Strauß, M. v. Ebner-Eschenbach und G. Heym . . . . . . 233

V.3 Schulmann, Antisemitismus und Unmensch. R. Musils > Die Verwirrungen des Zöglings Törleß<, J. R. Bechers ’Abschied ‘, A. Holz >Der erste Schultag، und H. Manns 'Der Untertan` . . . . . . . 244

Literaturverzeichnis . . . . . . . . . . . . . 257

Literarische, literaturkritische und philosophische Quellen ...................... 257

Bildungs- und sozialgeschichtliche Quellen .... . . 266

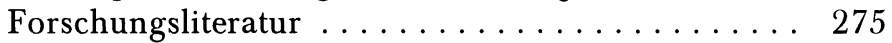

Personen- und Titelregister . . . . . . . . . . . 295 


\section{Vorbemerkung}

Die vorliegende Untersuchung wurde 1987 nach ersten Recherchen in der Herzog August Bibliothek Wolfenbüttel begonnen, 1992 in München abgeschlossen und kurze Zeit später von der Philosophischen Fakultät II der Ludwig-Maximilians-Universität München als Habilitationsschrift angenommen. Der Verfasser will nicht verschweigen, daß die Studie unter den Arbeitsbedingungen einer untragbar überlasteten Massenuniversität und unter den Vorzeichen einer als verantwortungsbewußt verkauften Stellenpolitik entstand, die jüngere Kollegen unnachsichtig und unentschuldbar um eine vielversprechende wissenschaftliche Laufbahn brachte. Um so mehr bedankt er sich bei seinem akademischen Lehrer, Prof. Dr. Wolfgang Martens, der das Forschungsvorhaben mit Entschlossenheit und stillem Vertrauen gefördert hat. Für die uneigennützige Unterstützung seiner Arbeit, ganz gleich, ob durch weiterführende Hinweise, zweckdienliche Empfehlungen, konstruktive Kritik oder die Beschaffung von entlegenem Material, ist der Verfasser Prof. Dr. John McCarthy, Kirsten Geissler, Dr. Wilhelm Haefs, Prof. Dr. Günter Häntzschel, Prof. Dr. Erich Kleinschmidt, Prof. Dr. Eckhardt Meyer-Krentler $\dagger$, Prof. Dr. Roger Paulin, Prof. Dr. Walter Schmitz, Dr. Christiane Raabe und - last, not least - Prof. Dr. Drs. hc. Paul Raabe Dank schuldig. Eine ganz besondere Erwähnung haben jedoch Katharina Festner und Peter Rossi verdient. Erstere hat das umfangreiche Manuskript in ihre Obhut genommen und entscheidend daran mitgewirkt, den Text rechtzeitig zum Druck zu befördern, letzterer hat auf unbewußte, aber ganz persönliche Weise dazu beigetragen, daß diese Untersuchung überhaupt zu Papier gebracht wurde. Ihnen beiden ist dieses Buch gewidmet. 